\title{
Daily Stock Price Behavior of Commercial Banks in Nepal
}

\author{
Keshar J. Baral \\ Surya Kumar Shrestha
}

\begin{abstract}
Using the data set on daily stock prices during the fiscal year 2005/06 (July 16, 2005 through July 16, 2006), this paper attempts to analyze the stock price behavior of commercial banks in Nepalese markets. The results of serial correlation and run tests conclude that the proposition of Random Walk Hypothesis (RWH) in Nepalese stock markets does not hold true. This conclusion corroborates with the conclusions of the past studies carried out in Nepalese context.
\end{abstract}

Key words: securities market, stock price behavior theories

THE SECURITIES MARKET PLAYS an important role in mobilizing savings and channeling them into productive investment for the development of commerce and industry in the country. It assists the capital formation and economic growth in the country. But, the Nepalese securities market still is in growing stage. Its further development is crucial. There are two approaches of predicting stock price behavior: the technical analysis and fundamental analysis. Briefly, technical analysis explains and forecasts changes in security prices by studying the market data. The technical analysts believe that the forces of supply and demand are reflected in the patterns of price and volume of trading while fundamental analysts do that economic environment and earning power are reflected in the pattern of market prices (Fischer and Jordan 2000). Technicians predict the stock price behaviour by analysing the pattern of price and volume of trading. But the fundamentalists predict the stock price behavior by analyzing earning power and the economic environment in the risk-return framework. The fundamentalists believe that at any point in time every share has an intrinsic value which should be in principle be equal to the present value of the future stream of income from that share discounted at an appropriate risk related rate of interest (Bhalla 1999). Thus, the actual price of the security is considered a function of a set of anticipated capitalization rate.

In Nepal, the major constituent of the securities market is the shares of commercial banks and behavior of price of commercial banks influences the Nepal Stock Exchange (NEPSE) index. This study examines the stock price behavior of listed commercial banks by using the daily price movements of 7 commercial banks sampled randomly in the fiscal year 2005/06.

\section{Theoretical Framework: Random Walk Hypothesis (RWH)}

We discussed that there are two approaches to predict the stock price behaviour. Randon walk hypothesis is the third approach to predict the stock price behavior and this is a weak form of the efficient-market hypothesis. This thoery raises the question on the belief of technicians. It, contradictory to the contention of technicians, pleads that pattern of stock price and volume of trading does not aid to predict the stock price behavior.

In more generalized term, random walk hyptohesis states that previous price changes or changes in return are useless in predicting future price or return changes. In other words, 
this model implies that an attemp to predict future prices using only historical price-change information is not successful. More precisely, this thoery contends that successive price changes are independent and prices at any time, on the average, reflect the intrinsic value of security (Fischer and Jordan 2000).

New information about the performance of the company comes out randomely. Different investors evaluate the available information differently and have different insight into future prospects of the firm. So, temporary stock price may deviate from its fair value. Professional investors, and well informed nonprofessional investors also seize the advantages arising from the random deviation from the intrinsic value. In other words, active selling and buying takes place in the markets to seize the advantages of deviation of market price from intrinsiv value of the stock. This active selling and buying of stock in question forces the price back to its equilibrium position.

\section{Related Past Studies}

A number of studies on RWH have been conducted abroad as well as in Nepal also. In Nepalese capital market context, most of the studies show that RWH does not hold true. Studies conducted by Aryal (1995), Shrestha (1999), Paudel (2003), Bajracharya (2003), Mainali (2003), Pradhan and Upadhay (2004), Shrestha (2004), and Paudel (2005) have tested the RWH in the context of Nepalese capital markets. All these studies have provided the evidences against the proposition of RWH. None of the studies shows that RWH hold true in Nepalese capital markets.

Some of the studies carried out abroad also have rejected the proposition of RWH. The study conducted by Blasco and Santamar (1997 in the Spanish stock market also provided evidence against the random walk hypothesis. Similarly, the study carried out by Smith, Jefferis and Ryoo (2001) have tested the RWH in five medium-sized markets: Egypt, Kenya, Morocco, Nigeria and Zimbabwe; and two small new markets: Botswana and Mauritius provided the evidence that the proposition of RWH does not hold true in all seven capital markets.

But some of the studies corroborate with the RWH. Zhu (1998) conducted a test of RWH in G-7 country stock price indices. This study shows the evidences in favor of RWH in G-7 country stock markets. The study conducted by Olowe (1999) in the context of Nigerian stock market also supports the proposition of RWH. Dahel and Laabas (1999) carried out a test of RWH on the capital markets of Bahrain, Kuwait, Oman and Saudi Arabia. They applied three tests of RWH: unit root, variance ratio, and autocorrelation of return. In the case of the Kuwaiti market, the results strongly have supported RWH. As to the other three markets, only autocorrelation of returns have rejected the proposition of RWH.

Similarly, Dockery, Vergari and Vergari (2001) have used 1988-1994 Greek monthly returns data to test the random walk behavior in share prices. The results of their study support the RWH in the Athens Stock Exchange. Thus, the review of past empirical studies shows the evidences for and against the proposition of RWH. On the whole, studies carried out in the growing capital markets show that the proposition of RWH does not hold true in developing capital markets and studies conducted in the developed capital markets show that it holds true especially in developed capital markets. 


\section{Methodology and Data}

There were 14 commercial banks listed to the Nepal Stock Exchange Ltd by July 16, 2005. Out of these, 7 commercial banks were sampled randomly. ${ }^{1}$ The required data were downloaded from www.bm.com.np, an official website of Business Manager and www.nepalstock.com, an official site of NEPSE. In addition, required data were collected from annual trading report of NEPSE 2005/06, national dailies: Kantipur, the Himalayan times, Gorkhaptra, the Rising Nepal. This study covers the observations of one fiscal year (July 16, 2005 to July 16, 2006). Total number of observations of the study is 1263: 183 from Himalayan Bank Ltd. (HBL), 189 from Nepal SBI Bank Ltd. (NSBIBL), 194 from Bank of Kathmandu Ltd. (BKL), 182 from Lumbini Bank Ltd. (LBL), 184 from Nepal Industrial and Commerce Bank Ltd. (NICBL), 176 from Kumari Bank Ltd. (KBL) and 155 from Laxmi Bank Ltd. (LXBL).

Descriptive statistical tools: mean, standard deviation (SD) and coefficient of variation $(\mathrm{CV})$ are used to analyze the volatility of the daily stock prices and indices of commercial banks and NEPSE. And inferential statistical tools: serial correlation and runs test are employed to measure the independence and the randomness in daily successive stock prices. SPSS application software has been used to work out mean , SD, CV and serial correlation; and Minitab application software to conduct the run test. At the same time, Microsoft Excel application software has been used to draw the charts.

As stated in the Theoretical Framework, proposition of RWH states that successive price changes are independent. The following hypotheses are tested to confirm this proposition of RWH:

$\mathrm{H}_{\mathrm{o}}$ : The successive or lagged price changes are independent.

$\mathrm{H}_{\mathrm{A}}$ : The successive or lagged price changes are dependent.

\section{Analysis of Stock Price Behavior}

\subsection{Technical Analysis}

This is the alternative approach to predict the stock price behavior. This approach is used as a supplementary to the fundamental analysis of stock price behavior. Unlike fundamentalists, technicians consider the pattern of the price to predict the stock price behavior. By examining the historical pattern of the stock prices, technicians predict whether prices are moving higher or lower. In addition, technicians predict by how much price will increase or decrease in future. Technical analysis is useful for timing a buy or sell order. Investors put off the buy a share if technicians predict that stock prices are further dropping in future. Conversely, investors postpone the selling order if technicians predict that prices further are increasing in near future.

In this section trend of daily stock price of sampled banks has been worked out by using the least square method and plotted along with the actual observations of individual banks. Calculated trend line and actual stock price of sampled banks are plotted in Fig. 1 to Fig. 7 given on the ensuing pages. The slop of trend lines of stock prices of 6 sampled banks is positive and 1 bank is negative. LBL has negative slop and it implies that its stock

\footnotetext{
${ }^{1}$ Sample includes Himalayan Bank Ltd., Nepal SBI Bank Ltd., Bank of Kathmandu Ltd., Lumbini Bank Ltd., Nepal Industrial and Commerce Bank Ltd., Kumari Bank Ltd. and Laxmi Bank Ltd.
} 
price is in decreasing trend, but all other banks have increasing trend in their stock price during the observed fiscal year.

Fig. 1: Daily Stock Price Behavior of HBL

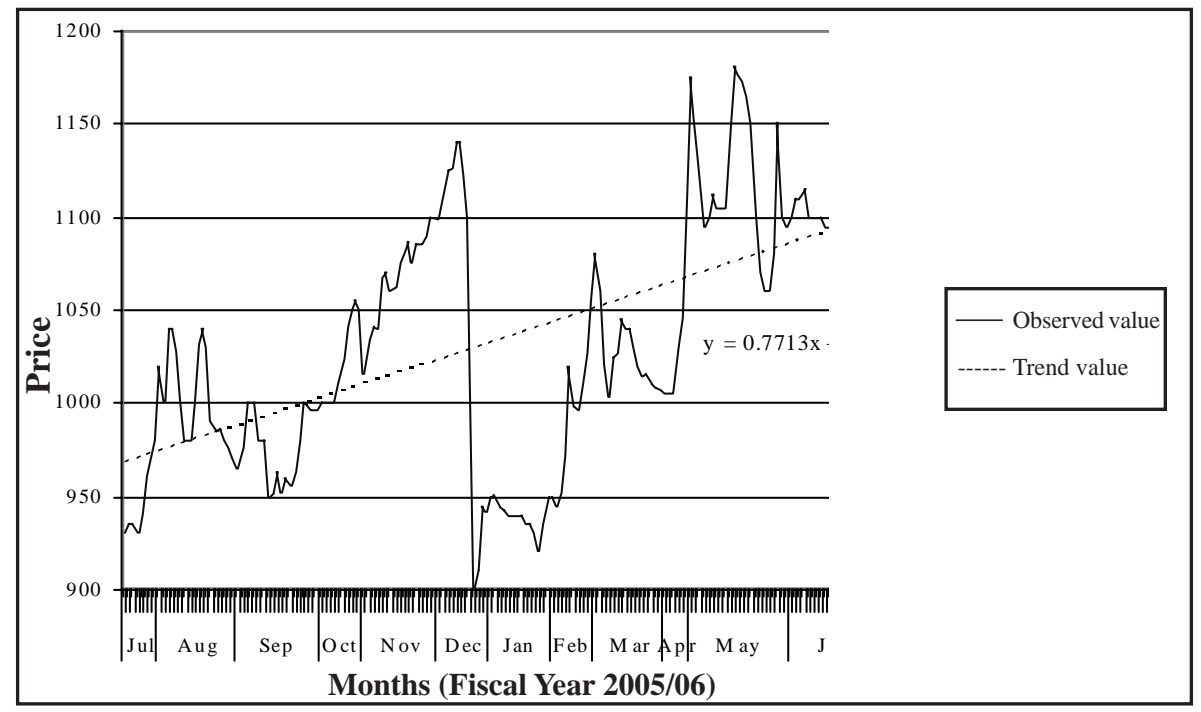

Fig.1 exhibits the daily stock prices behavior of HBL. The maximum price of HBL stock is Rs.1181 in May 15, 2006, the minimum is Rs.900 in December 25, 2005 and the average price is Rs.1037.62. There is a sudden fall in the stock price of HBL in the month of December. In that month, stock price fell from Rs. 1140 to Rs.900. The stock price of HBL, on the average, tends to increase during the first six months and fell in the last week of December and again tends to rise until the end of the year. On the whole, stock price is in increasing trend during the observed year.

Fig. 2: Daily Stock Price Behavior of NSBIBL

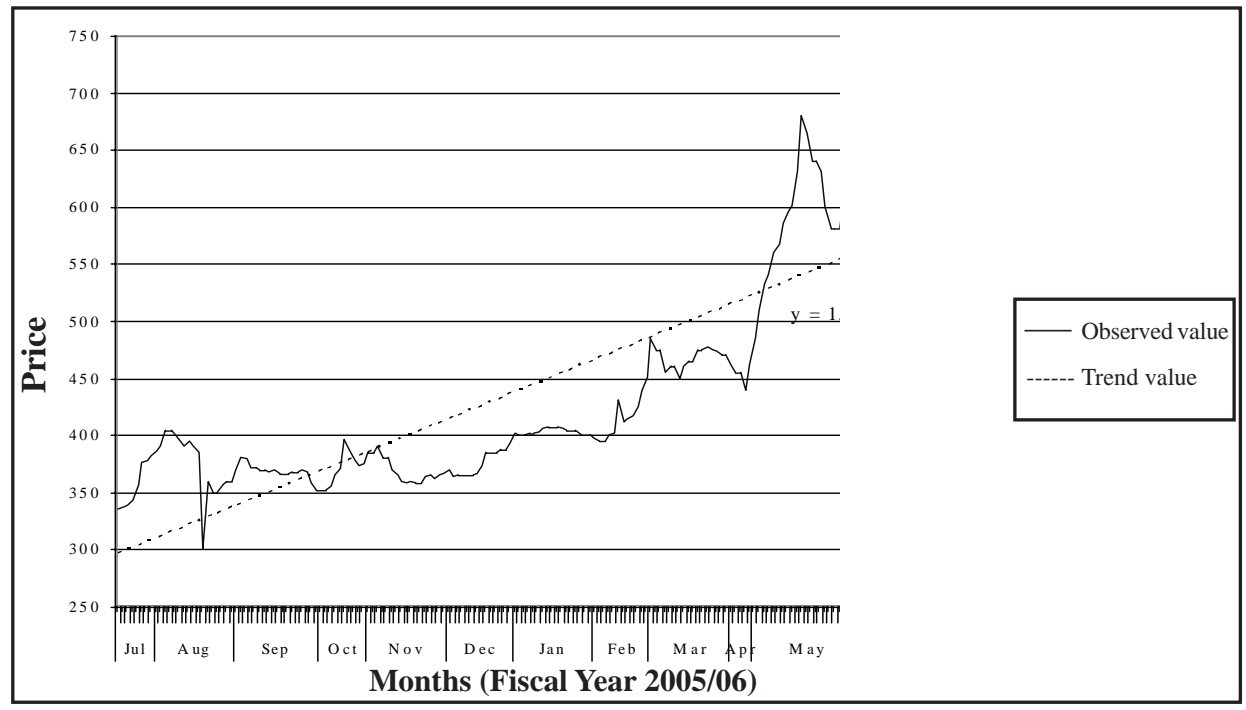


Fig.2 exhibits the daily variation in the stock prices of NSBIBL. The maximum stock price of NSBIBL is Rs.680 in May 15, 2006, the minimum is Rs.300 in August 17, 2005 and the average price is Rs.454.60. There is a high variation in stock prices during the observed fiscal year. The coefficient of linear equation is 1.6789 and it shows the increasing pattern in the stock prices of NSBIBL during the study period.

Fig. 3: Daily Stock Price Behavior of BOK

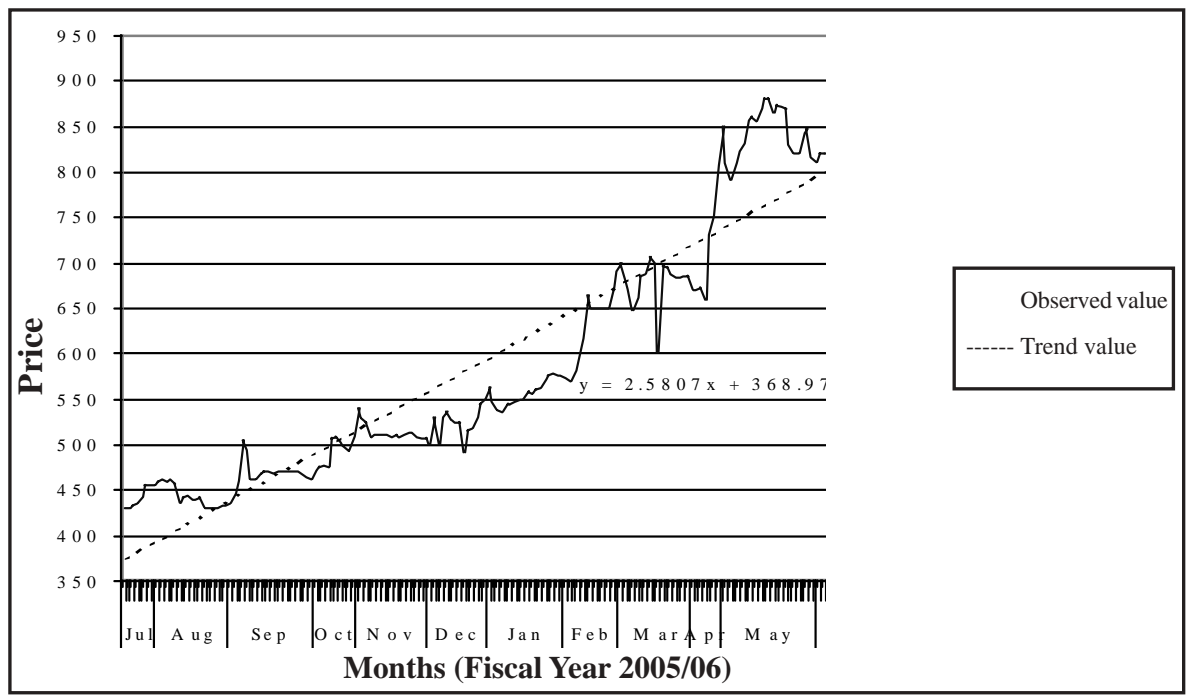

Fig. 3 shows that the maximum stock price of BKL is Rs. 881 in May 15, 2006, the minimum is Rs.430 in July 18, 2005 and the average price is Rs.620.60. The graph exhibits that the stock prices of BKL is the most volatile in nature. The high positive coefficient of linear equation indicates the rising pattern in the stock prices of BKL. This signifies that the position of BKL stock is very strong in the secondary market.

Fig. 4: Daily Stock Price Behavior of NICBL

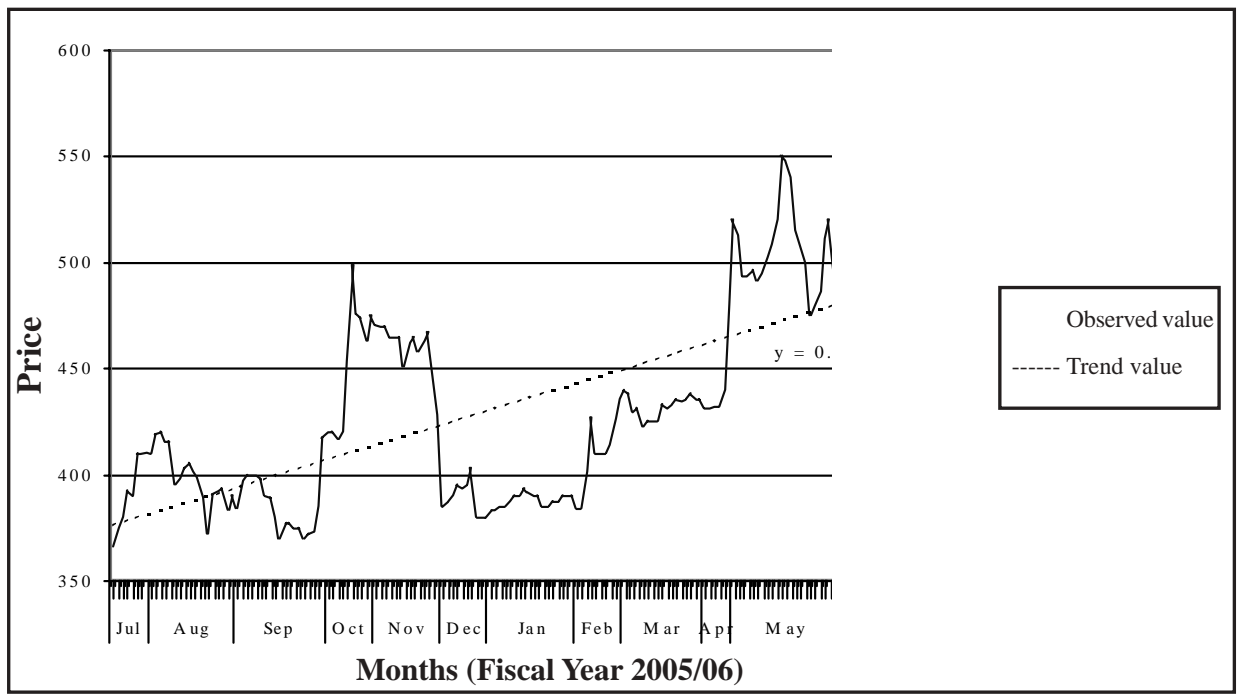


Fig. 4 shows the daily stock price movement of NICBL. The maximum stock price of NICBL stock is Rs.580 in June 4, 2006, the minimum is Rs.366 in July 17, 2005 and the average price is Rs.438.92. The graph of daily stock price of NICBL shows the erratic pattern between Rs.580 and Rs.366. On the whole, it is in increasing trend during the study year.

Fig. 5: Daily Stock Price Behavior of LXBL

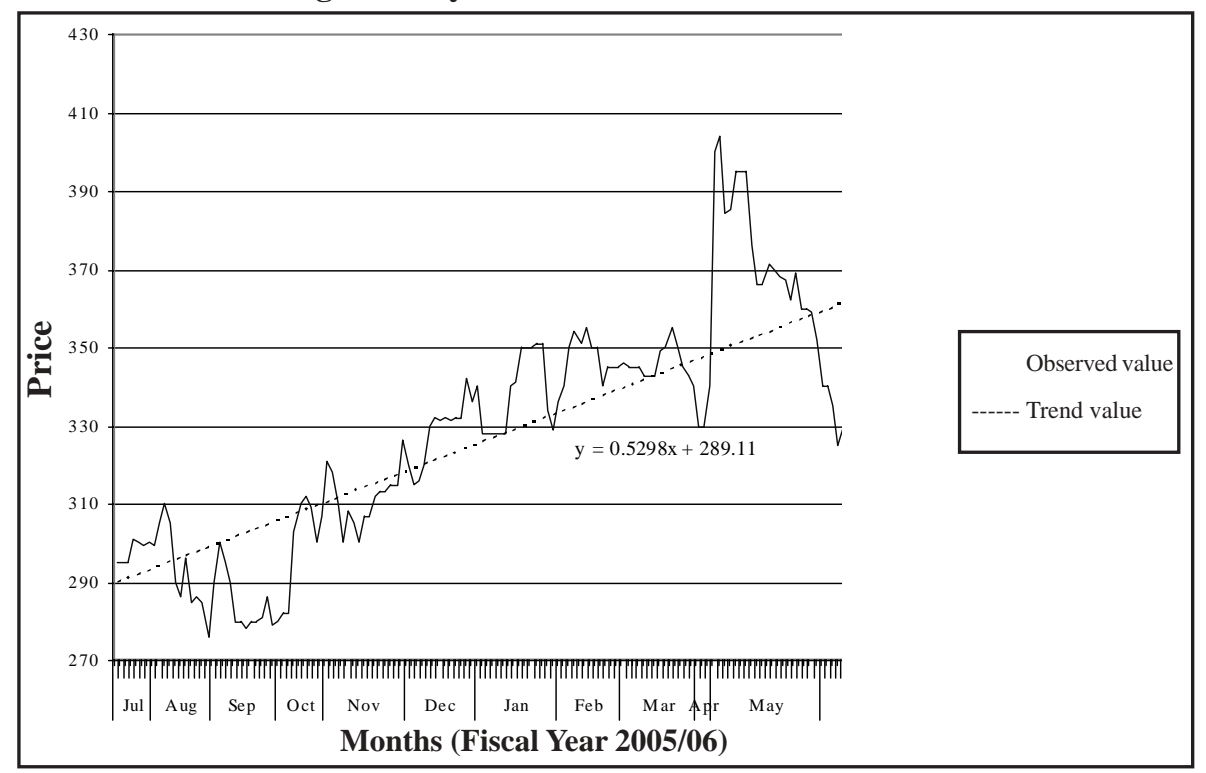

Fig. 5 demonstrates the daily stock price movement of LXBL. The maximum stock price is Rs.404 in May 2, 2006, the minimum is Rs.276 in May 23, 2005 and the average price is Rs.330.43. The slop of trend line is positive but very dismal during the observed fiscal year.

Fig. 6: Daily Stock Price Behavior of KBL

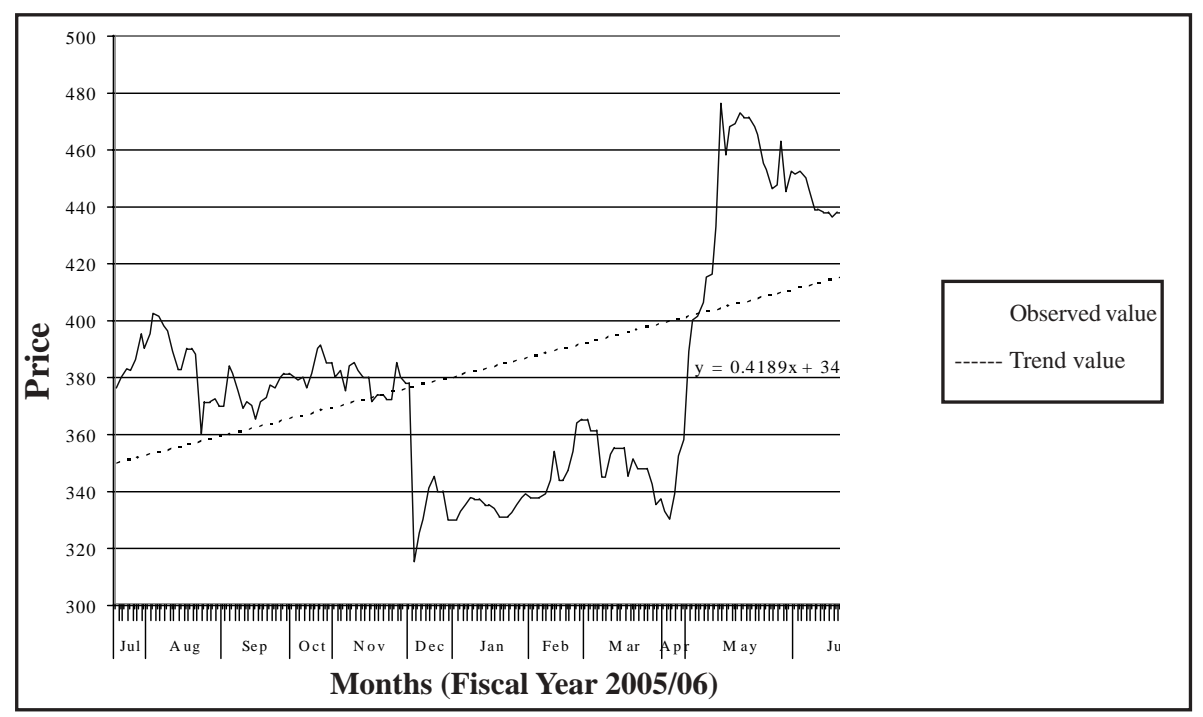


Fig. 6 show that the daily stock price of KBL is highly fluctuating. Maximum price of its stock is Rs.476 in May 10, 2006, the minimum is Rs.315 in December 8, 2005 and the average price is Rs.386.09. Fluctuation in its stock prices makes many crests and troughs during the year. However, the daily stock price is in increasing trend.

Fig. 7: Daily Stock Price Behavior of LBL

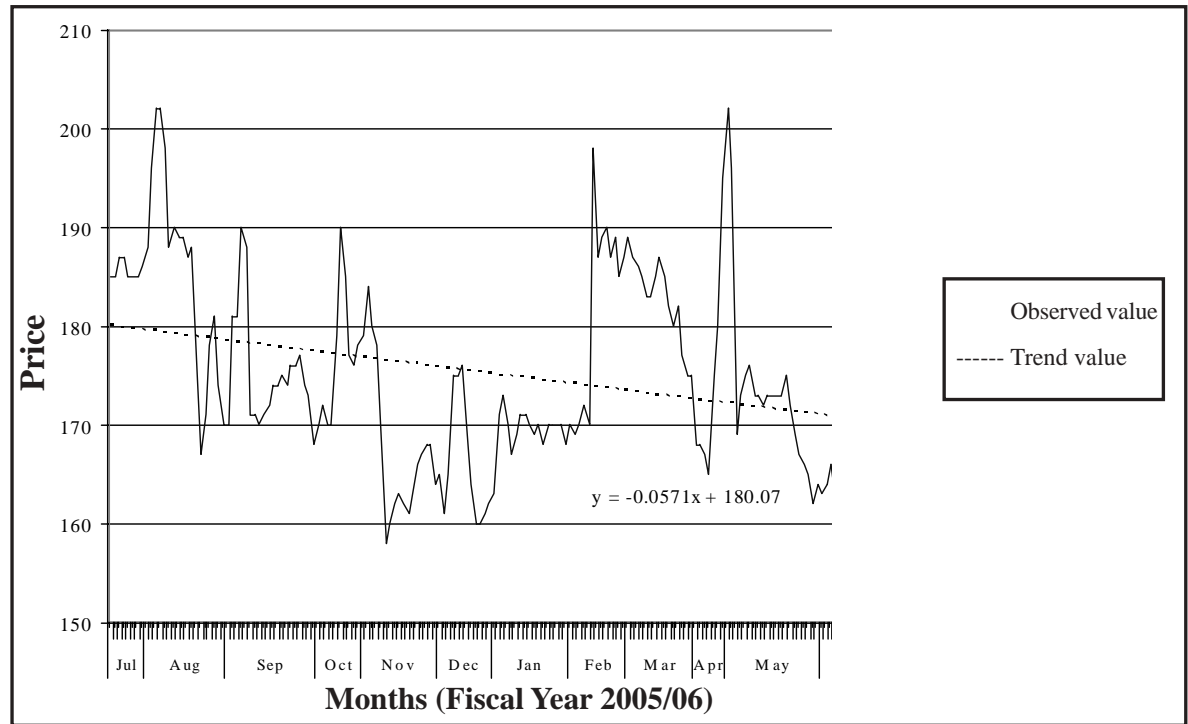

The stock price of LBL is highly fluctuating during the observed year. Maximum price of its stock is Rs. 202 in May 1, 2006, the minimum is Rs. 158 in November 15, 2005 and the average price is Rs.174.84. On the average, its daily stock price is in decreasing trend. The down turn trend in stock price signals relatively weak performance of LBL in the capital market.

It is noteworthy that the stock prices of all sampled banks have dipped in the month of April and started to recover at the end of May. The fundamental reason behind this is the fear of political instability from the second Popular Movement 2006 (20062/063) and expectation of political stability after overcoming the autocratic kingship and restoration of democracy in the third time in the country. After the end of second Popular Movement, stock price of all banks have shown the tendency of recovery in the markets.

Though the graphical presentation of the daily stock price visualizes the general stock price movement but it does not precisely show the spread of the daily stock price during the study period. Indicators of volatility (spread) of stock price of each sampled bank are given in Appendix 3. All indicators: range, SD and CV, evidence that stock price of BKL is the most volatile during the study period, and then, stock price of NSBIBL comes in the order of volatility. Stock price of LBL is the least volatile during the study period. It would not be prudent to draw the conclusion that investment in BKL is the most risky and LBL is the least risky at this juncture without analyzing the earning and other financial indicators of these banks. HBL, NICBL, LXBL and KBL are the mediocre in respect to volatility of stock price during the study period.

\subsection{Test of Random Walk Hypothesis}

As stated in methodology, independency of successive price is tested using the serial corre- 
lation and run tests. In this section, first, results of serial correlation are analyzed and then of run tests.

Analysis of the Results of Serial Correlation: Out of the seventy computed serial correlation coefficients, only five coefficients are greater than two times but less than three times of their S.E. (refer to Appendix 1.1 and 1.2). Similarly, seven coefficients are equal to three or greater than three times of their S.E. However, the large number (fifty-eight) of coefficients fall in the category of less than or equal to two times of S.E. These coefficients are significantly deviated from zero and not statistically significant. It implies that the successive price changes are dependent. Thus, $\mathrm{H}_{\mathrm{O}}$ stated in Methodology has been rejected and $\mathrm{H}_{\mathrm{A}}$ been accepted. This result corroborates with the findings of the previous studies (Pradhan and Upadhay 2004 and Paudel 2005).

Analysis of the Results of Run Test: Positive sign has dominated the computed values of Z, standardized normal variate (refer to Appendix 2.1). Similarly, the negative sign has dominated the computed values of $\mathrm{K}$. The negative results are due to the reason of higher expected number of runs over the observed number of runs. To verify the runs test result, the percentage of deviation has been computed.

Out of seven equity shares, two are less than five percent and five are greater than five percent (refer to Appendix 2.3). The percentage differences for half of the equity shares are greater than ten percent. In general, results show that there is a significant difference between the expected and actual number of runs in the series of price changes. It implies that the RWH does not hold true in the context of Nepalese stock market. This evidence too, corroborates with the results of the previous studies ((Pradhan and Upadhay 2004, and Paudel 2005).

\section{Conclusions}

Observations of daily stock prices of sampled banks indicate that there is a large variation in their stock prices in the fiscal year 2005/06. They are not doing well in Nepalese stock market. Most of the serial coefficients are significantly deviated from zero and statistically insignificant. It signifies that the successive price changes are dependent. Therefore, the Nepalese stock market is inefficient in pricing the shares. Runs test results also show that the percentage of deviation between the observed and actual number of runs in the series of price changes is significant. It is obvious that the successive price changes are not random. Thus, RWH does not hold true in the context of Nepalese stock market.

\section{Appendix 1.1: Serial Correlation Coefficients of the Stocks}

\begin{tabular}{|c|c|c|c|c|c|c|c|c|c|c|}
\hline Companies\Lag & 1 & 2 & 3 & 4 & 5 & 6 & 7 & 8 & 9 & 10 \\
\hline HBL & -0.371 & -0.100 & 0.002 & -0.101 & 0.041 & 0.056 & -0.030 & -0.027 & -0.006 & 0.027 \\
\hline NSBIBL & -0.539 & 0.064 & -0.015 & 0.019 & 0.016 & -0.047 & 0.075 & -0.120 & 0.067 & 0.047 \\
\hline BKL & -0.507 & -0.018 & 0.080 & -0.123 & 0.005 & 0.151 & -0.159 & 0.113 & -0.024 & -0.080 \\
\hline NICBL & -0.517 & 0.073 & -0.147 & 0.077 & 0.070 & -0.076 & 0.043 & -0.077 & 0.058 & 0.050 \\
\hline LXBL & -0.329 & -0.204 & -0.002 & -0.039 & 0.106 & 0.096 & -0.197 & 0.003 & 0.016 & 0.140 \\
\hline KBL & -0.544 & 0.051 & 0.042 & -0.089 & 0.013 & -0.001 & 0.092 & -0.114 & 0.118 & -0.046 \\
\hline LBL & -0.410 & -0.036 & -0.071 & -0.076 & 0.092 & -0.022 & 0.041 & 0.033 & -0.019 & -0.094 \\
\hline
\end{tabular}




\section{Appendix 1.2: Standard Error (S.E.) of the Stocks}

\begin{tabular}{lcccccccccc}
\hline CompaniesLLag & $\mathbf{1}$ & $\mathbf{2}$ & $\mathbf{3}$ & $\mathbf{4}$ & $\mathbf{5}$ & $\mathbf{6}$ & $\mathbf{7}$ & $\mathbf{8}$ & $\mathbf{9}$ & $\mathbf{1 0}$ \\
\hline HBL & 0.074 & 0.074 & 0.073 & 0.073 & 0.073 & 0.073 & 0.072 & 0.072 & 0.072 & 0.072 \\
NSBIBL & 0.073 & 0.072 & 0.072 & 0.072 & 0.072 & 0.072 & 0.071 & 0.071 & 0.071 & 0.071 \\
BKL & 0.072 & 0.071 & 0.071 & 0.071 & 0.071 & 0.071 & 0.070 & 0.070 & 0.070 & 0.070 \\
NICBL & 0.074 & 0.073 & 0.073 & 0.073 & 0.073 & 0.072 & 0.072 & 0.072 & 0.072 & 0.072 \\
LXBL & 0.080 & 0.080 & 0.080 & 0.079 & 0.079 & 0.079 & 0.078 & 0.078 & 0.078 & 0.078 \\
KBL & 0.075 & 0.075 & 0.075 & 0.075 & 0.074 & 0.074 & 0.074 & 0.074 & 0.073 & 0.073 \\
LBL & 0.074 & 0.074 & 0.074 & 0.073 & 0.073 & 0.073 & 0.073 & 0.072 & 0.072 & 0.072 \\
\hline
\end{tabular}

Appendix 1.3: Series Having Significant Values of First to Tenth Order Serial Correlation Coefficients

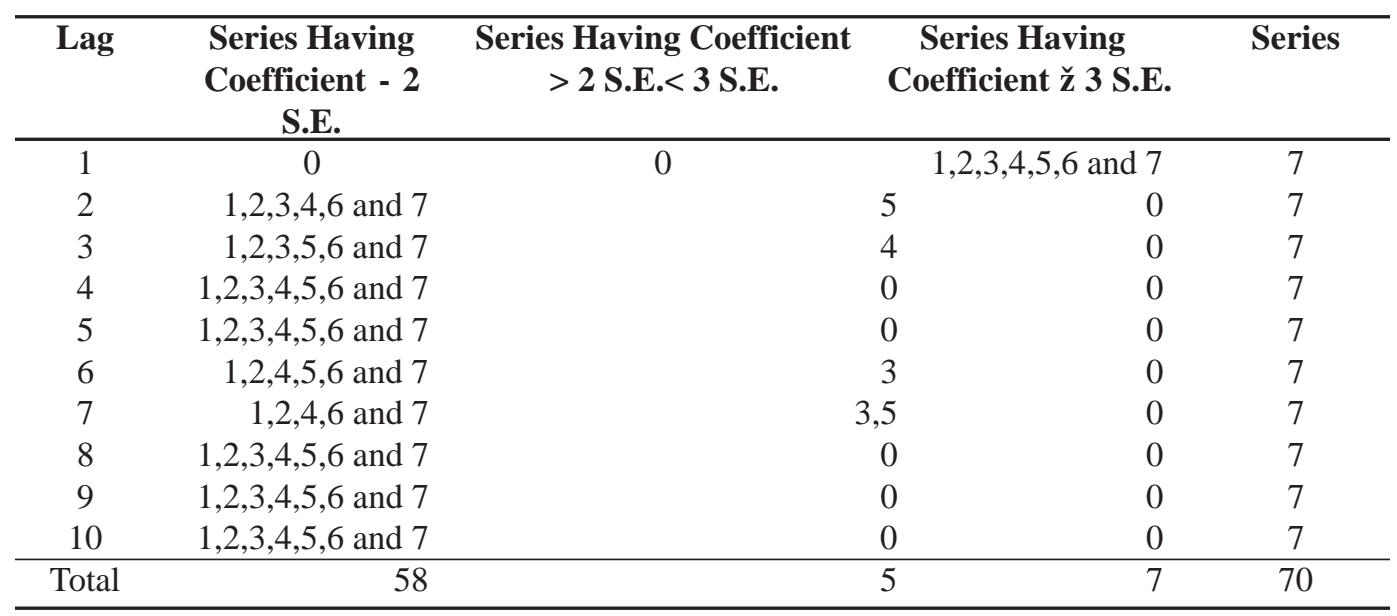

Appendix 2.1: Distribution of Signs of Coefficients

\begin{tabular}{cccc}
\hline Lag & Number of +sign & Number of -sign & Total \\
\hline 1 & 0 & 7 & 7 \\
2 & 3 & 4 & 7 \\
3 & 3 & 4 & 7 \\
4 & 2 & 5 & 7 \\
5 & 6 & 1 & 7 \\
6 & 3 & 4 & 7 \\
7 & 4 & 3 & 7 \\
8 & 3 & 4 & 7 \\
9 & 4 & 3 & 7 \\
10 & 4 & 3 & 7 \\
\hline Total & 32 & 38 & 70 \\
\hline
\end{tabular}

Appendix 2.2: Computation of Runs Test

\begin{tabular}{clcccc}
\hline S.no. & Companies & $\boldsymbol{\mu r}$ & $\mathbf{r}$ & $\mathbf{Z}$ & $\mathbf{K}=\mathbf{r}-\boldsymbol{\mu}_{\mathbf{r}} / \boldsymbol{\mu}_{\mathbf{r}}$ \\
\hline 1 & HBL & 89.8462 & 68 & 0.9341 & -0.2432 \\
2 & NSBIBL & 90.3085 & 67 & 1.4681 & -0.2581 \\
3 & BKL & 86.5544 & 64 & 2.1710 & -0.2606 \\
\hline
\end{tabular}




\begin{tabular}{clllll} 
Appendix 2.2 (Continued) & \multicolumn{5}{l}{} \\
\hline 4 & NICBL & 91.0546 & 86 & 0.7104 & -0.0555 \\
5 & LXBL & 76.4286 & 76 & 0.4740 & -0.0056 \\
6 & KBL & 86.9886 & 66 & 0.3829 & -0.2413 \\
7 & LBL & 87.2983 & 85 & -0.0718 & -0.0263 \\
\hline
\end{tabular}

Appendix 2.3: Percentage Difference between the Observed and Expected Number of Runs as Proportions of Expected Number of Runs

\begin{tabular}{ccc}
\hline S.no. & Percentage of Equalities and Inequalities of K & Number of K \\
\hline 1 & K having percent difference - 5 & 2 \\
2 & K having percent difference 5- 10 & 1 \\
3 & K having percent difference - 10 & 4 \\
\hline & Total & 7 \\
\hline
\end{tabular}

Appendix 3: Indicators of Volatility of Stock Price of Each Sampled Bank

\begin{tabular}{rlcccccrr}
\hline S.no. & $\begin{array}{l}\text { Sampled } \\
\text { Banks }\end{array}$ & $\begin{array}{c}\text { No. of } \\
\text { Observations }\end{array}$ & $\begin{array}{c}\text { Max. } \\
\text { Price }\end{array}$ & $\begin{array}{l}\text { Min. } \\
\text { Price }\end{array}$ & Range & $\begin{array}{c}\text { Average } \\
\text { Price }(\boldsymbol{\mu})\end{array}$ & $\begin{array}{r}\text { SD } \\
(\boldsymbol{\sigma})\end{array}$ & $\begin{array}{r}\text { CV } \\
(\boldsymbol{\%})\end{array}$ \\
\hline 1 & HBL & 183 & 1181 & 900 & 281 & 1037.62 & 67.29 & 6.00 \\
2 & NSBIBL & 189 & 680 & 300 & 380 & 454.60 & 103.30 & 23.00 \\
3 & BKL & 194 & 881 & 430 & 451 & 620.59 & 151.93 & 24.00 \\
4 & NICBL & 184 & 580 & 366 & 214 & 438.92 & 49.58 & 11.00 \\
5 & LXBL & 155 & 404 & 276 & 128 & 330.43 & 29.12 & 9.00 \\
6 & KBL & 176 & 476 & 315 & 161 & 386.09 & 42.15 & 11.00 \\
7 & LBL & 182 & 202 & 158 & 44 & 174.84 & 9.57 & 5.00 \\
\hline
\end{tabular}

\section{REFERENCES}

Aryal, Mukti. 1995. "The General Behavior of Stock Market Prices." MBA diss., Tribhuvan University.

Bajracharya, Rajiv. 2003. "Stock Price Behavior of Financial Institutions in Nepal." MBS diss., Tribhuvan University.

Bhalla, V.K. 1999. Investment Management: Security Analysis and Portfolio Management. 6th ed. New Delhi: S. Chand \& Company Ltd.

Blasco, Natividad, Cristina Del Rio and Rafael Santamar'a. 1997. The Random Walk Hypothesis in the Spanish Stock Market: 1980-1992. Journal of Business Finance and Accounting 24:667. Aug.8, 2006 <http://www.blackwell-synergy.com/doi/abs/ 10.1111/1468-5957.00128?prevSearch=allfield\%3A\%28 efficiency+market+hypothesis\%29>.

Dahel R. and B. Laabas. 1999. "The Behavior of Stock Prices in the GCC Markets." Papers 9917:17. Aug.13, $2006<\mathrm{http} / / /$ ideas.repec.org/p/fth/ecrefo/9917.html>.

Dockery, E., D. Vergari and F. Vergari. 2001. Explaining the Behavior of Stock Prices in an Emerging Market: an Empirical Analysis of the Greek Stock Market. Managerial Finance 27: 82-98, Aug.8, 2006 <http:/ /www.emeraldinsight.com/Insight/viewContentItem.do? contentType=Article\&contentId=865730>.

Fischer, Donald E. and Ronald J. Jordan. 2000. Security Analysis and Portfolio Management. 12th Indian Reprint. New Delhi: Prentice Hall of India Pvt. Ltd.

Mainali, Mahesh. 2003. "A study on Share Price Behavior of Listed Commercial Banks." MBS diss., Tribhuvan University.

Olowe, R. Ayodeji. 1999. Weak Form Efficiency of the Nigerian Stock Market: Further Evidence. African Development Review 11: 54. Aug.11, 2006 <http://www.blackwell-synergy. com/doi/abs/10.1111/14678268.00003 ? prevSearch=allfield\%3A\%28weak+form+of+efficiency\%29>.

Paudel, Gurudatta. 2003. "A Study on the Movement of Stock Prices in Relation to Joint Venture Commercial banks." MBS diss., Tribhuvan University. 
Paudel, Resham Lal. 2005. "Share Price Behavior of Listed Companies in Nepal." MBS diss., Tribhuvan University.

Pradhan, Radhe S. and Basu D. Upadhyay. 2004. The Efficient Market Hypothesis and the Behavior of Share Prices in Nepal. The Nepalese Management Review 12:1-27.

Shrestha , Manohar K. and Dipak B. Bhandari. 2004. Financial Markets and Institutions. Kathmandu: Asmita Books Publishers and Distributors.

Shrestha, Surya Chandra. 1999. "A study on Stock Price Behavior in Nepal." MBA diss., Tribhuvan University. Shrestha, Surya Kunwar. 2006. "Daily Stock Price Behaviour of Commercial Banks in Nepal." MBS diss. TU.

Smith, Graham, Keith Jefferis and Hyun-Jung Ryoo. 2001. African Stock Markets: Multiple Variance Ratio Tests of Random Walks. Applied Financial Economics 12: 475-484. Aug.2, 2006 <http:// taylorandfrancis.metapress.com/(h3wgy0a30quli455iltkr155)/app/home/contribution.asp? Referrer=parent\&backto=issue, 3, 8; journal, 65,106; linkingpublicationresults, 1:101479,1>.

Zhu, Zhen. 1998. The Random Walk of Stock Prices: Evidence from a Panel of G-7 Countries. Applied Economics Letters 5: 411-13. Aug.6, 2006 <http://taylorandfrancis.metapress.com/ (5bqijobv10chi5rwubcwyvqk)/app/home/contribution.asp? Referrer=parent\&backto=issue, 2,16;journal, 111,148;linkingpublicationresults, 1:101478,1>. 